\title{
Atualizando o debate sobre o cenário normativo publicitário ante o público infantil: um estudo comparativo entre Brasil e Espanha ${ }^{1}$
}

\author{
Upgrading the discussion about the regulatory landscape advertising \\ on children: a comparative study between Brazil and Spain
}

\section{Ana Paula Bragaglia}

Doutora em Psicologia Social pela Universidade do Estado do Rio de Janeiro (UERJ), professora de Ética e Legislação Publicitária na Universidade Federal Fluminense (UFF), Niterói, RJ - Brasil, e-mail: apbragaglia@yahoo.com.br.

\section{Resumo}

Pretende-se descrever o cenário normativo brasileiro referente à publicidade infantil, analisando tanto o que está em vigor quanto novas alternativas ético-legais atualmente sob análise, bem como comparar tais diretrizes com os princípios correlatos encontrados na Espanha. A metodologia utilizada é a revisão bibliográfica, principalmente em livros de autores brasileiros e espanhóis sobre a normatização e a influência da propaganda voltada a menores e em leis ou projetos de lei e códigos de ética, de ambos os países, que abordam este tema. Como principais resultados, verificou-se que o Brasil se mostra bastante preocupado com este assunto, parecendo até mesmo ultrapassar os cuidados da sociedade espanhola nesse ramo, como demonstram o projeto de lei 5921/01, que trata da proibição completa desse tipo de anúncios, e, ainda, novos regulamentos da Anvisa em discussão.

Palavras-chave: Publicidade. Ética profissional. Regulamentação profissional. Criança.

\begin{abstract}
This paper aims to describe the Brazilian legal landscape for advertising to children, looking at both what is in effect as new ethical-legal alternatives currently under review and compare these guidelines with the related principles found in Spain. The methodology used is the literature review mainly in books by Brazilian and Spanish on the regulation and the influence of advertising aimed at children and laws or draft laws and codes of ethics of both countries about the topic. As main results, it was found that Brazil is very concerned about this matter, even looking beyond the care of Spanish society in this field, as shown by the draft law 5921/01 which intends the complete probibition of such advertisements, and also new Anvisa regulations under discussion.
\end{abstract}

Keywords: Advertising. Ethics. Regulation. Child.

1 O artigo é parte da referida tese de doutorado concluída em 2009. Durante os seis penúltimos meses as pesquisas foram feitas em Madri (PDEE/Capes). 


\section{Introdução}

Este artigo apresenta as principais diretrizes, códigos de ética e textos legais atuais e em discussão voltados a normatizar a publicidade infantil, ou seja, dirigida a crianças (menores de 12 anos, segundo o Estatuto da Criança e do Adolescente, os códigos espanhóis e vários outros documentos), bem como comparar tal cenário com o que se vê na Espanha nesse sentido. A escolha dessa base comparativa se justifica porque a Espanha, pelo menos em termos de autorregulamentação, está entre os países mais bem avaliados pela European Advertising Standard Association(Easa), ${ }^{2}$ ultrapassando França, Alemanha e Itália (não foram encontrados dados desse tipo sobre o sistema legal espanhol) (SCHNEIDER, 2005, p. 22). Também explica a escolha, a existência de contatos acadêmicos no país e a familiaridade cultural com este.

Antes de analisar os cenários escolhidos comenta-se brevemente sobre aspectos que os embasam, como a subjetividade na infância, os possíveis efeitos da publicidade na criança, as peculiaridades desse público diante da sociedade midiática atual e os demais modelos normativos internacionais para além do espanhol.

Pesquisas sobre a influência da propaganda em menores sustentam conclusões como as de Bree (1995) e Kapferer (1985), de que crianças de 0 a 5 anos não sabem diferenciar uma propaganda de outro programa midiático; as de 6 a 7 conseguem perceber um caráter informativo no anúncio; as de 8 começam a perceber uma função de persuasão; mas somente entre 8 e 11 a maior parte delas está realmente capacitada para adquirir tal consciência (MONTOYA VILAR, 2007, p. 56). As preocupações com a publicidade infantil se justificam também pelo contínuo contato das crianças com a televisão e o cenário peculiar desta sociedade de consumo, no qual mensagens publicitárias estão presentes nos mais diferentes momentos e locais. São argumentos mais específicos que embasam os cuidados com tais propagandas: a possibilidade de algumas estimularem a obesidade infantil, a sexualidade precoce, o constrangimento de pais e responsáveis por meio da insistência pela compra e consequentes endividamentos, a sensação de discriminação diante de quem possui o produto ofertado, entre outros comportamentos vistos como reprováveis socialmente (ALANA, 2010).

$\mathrm{Na}$ Espanha, segundo pesquisa publicada no El País, em 2003, crianças de 4 a 12 anos ficaram, em 2002, em torno de 2,5 horas diante da TV, tempo em que observaram cerca de 50 comerciais (MONTOYA VILAR, 2007, p. 17-20). No Brasil, os números praticamente dobram. Em 2005, segundo pesquisa do Ibope (Painel Nacional de Televisão), as crianças brasileiras (4 a 11 anos) foram as que mais assistiram TV no mundo, com uma média de aproximadamente 5 horas $(4 \mathrm{~h} 51 \mathrm{~min} 19 \mathrm{~s})$, superando até mesmo as dos Estados Unidos (PORTAL APRENDIZ, 2007).

Como destaca Klein (2004), nem nas escolas o público infantil fica distante dos reclames. A emissora Channel One, por exemplo, fez com que diversas delas "abrissem suas salas de aula para dois minutos de publicidade televisiva por dia, espremidos entre vinte minutos de programação de assuntos atuais de interesse dos adolescentes moderninhos". As instituições aceitaram a proposta porque não recusariam receber gratuitamente aparelhos de TV (e, em alguns casos, computadores), mas não sabiam que não poderiam desligar ou abaixar o volume do aparelho durante os minutos comerciais acoplados ao "presente" (KLEIN, 2004, p. 113-114).

Em Québec, desde 1980, vigora a Lei 72 (de proteção ao consumidor), proibindo a veiculação, em qualquer mídia, de propagandas de produtos para pessoas com menos de 13 anos, restrição também encontrada na Noruega no caso de anúncios em TV (MOMBERGER, 2002, p. 85-86). Na Suécia, desde 1991, ficou proibida a publicidade dirigida a menores de 12 anos em TV e rádio antes das 21 h e durante e imediatamente antes e depois de programas infantis (MOMBERGER, 2002, p. 83-84). Além disso, são transmitidos programas educativos como o semanal da cadeia SVTI, criado "especialmente para ensinar às crianças de $9 \mathrm{a} 14$ anos a converterem-se em consumidores prevenidos" (MONTOYA VILAR, 2007, p. 92). $\mathrm{Na}$ Grécia, entre $7 \mathrm{~h}$ e $22 \mathrm{~h}$, não podem ser veiculados em TV anúncios de brinquedos e estuda-se se a restrição deve ser estendida a outros produtos (MOMBERGER, 2002, p. 85). Na Dinamarca e na Bélgica é proibida a publicidade durante programas infantis e também cinco minutos antes e depois destes

\footnotetext{
2 Organismo sediado na Bélgica, criado em 1992, que congrega e monitora cerca de 25 organismos de autorregulamentação publicitária do mundo todo e realiza uma série de ações em prol da ética no setor.
} 
(ALANA, 2010). Embora não proíbam a publicidade infantil, Alemanha, Bélgica e Inglaterra criaram, assim como Noruega e Dinamarca, canais televisivos infantis sem qualquer tipo de publicidade (MONTOYA VILAR, 2007, p. 82-83). Na Inglaterra, todo e qualquer anúncio deve passar pelo crivo de determinados órgãos antes de ser veiculado (MOMBERGER, 2002, p. 81). Áustria e Portugal pró́bem propagandas em escolas e Luxemburgo só permite esse tipo de veiculação mediante autorização governamental (MOMBERGER, 2002, p. 132). Nos EUA, embora desde 1990 exista a Lei de Televisão Infantil, várias mobilizações vêm ocorrendo por conta de seus artigos serem considerados brandos (MONTOYA VILAR, 2007, p. 81). Entre as solicitações, está a proibição da publicidade de alimentos para crianças em TV e o impedimento de empresas anunciarem em escolas (MOMBERGER, 2002, p. 81).

\section{O cenário normativo da publicidade infantil no Brasil}

No Brasil, as restrições à publicidade infantil situam-se principalmente no artigo 37 e no anexo H do Código Nacional de Autorregulamentação Publicitária (Conar), no artigo 37 do Código de Defesa do Consumidor (CDC) Lei 8.078 (CDC, 2009) e em regulamentações da Agência Nacional de Vigilância Sanitária (Anvisa) e não contemplam ainda medidas mais rigorosas como a proibição legal da veiculação desse tipo de anúncio, seja total ou em alguma faixa de horário. No entanto, o debate está em pleno vapor, tendo sido retomado em 2003 quando cogitou-se a proibição de anúncios de bebidas alcoólicas, e impulsionado ainda mais, principalmente, em 2004 e 2009, com a discussão do Projeto de Lei (PL) 5.921/01 elaborado em 2001 pelo deputado Luiz Carlos Hauly (PSDB, PR) (REBOUÇAS, 2008). Nesses e em outros documentos brasileiros não há uma definição clara sobre quando uma propaganda é voltada a menores. O referido PL define apenas que serão assim classificados os anúncios de produtos voltados "apenas" a crianças.

Segundo o Conar, em seu artigo 37 (seção 11 Crianças e Adolescentes) reproduzido na sequência (foram excluídos os itens de algum modo enquadrados nos que estão citados), nenhum anúncio deve conter frases no imperativo voltadas a crianças (como
"Peça para o seu pai") ou alguém dialogando diretamente com esse público (apelo direto) (CONAR, 2009). Além disso, os anúncios não devem desprezar valores como amizade, respeito à natureza e ao ser humano, honestidade, entre outros; estimular comportamentos discriminatórios, inclusive por não se possuir o produto divulgado; incentivar situações de risco à saúde; encorajar o constrangimento de pais ou responsáveis propiciado pela insistência naquela compra; e utilizar crianças em anúncios de produtos a elas inadequados (bebidas alcoólicas, por exemplo) (CONAR, 2009).

Artigo 37 - Os esforços de pais, educadores, autoridades e da comunidade devem encontrar na publicidade fator coadjuvante na formação de cidadãos responsáveis e consumidores conscientes. Diante de tal perspectiva, nenhum anúncio dirigirá apelo imperativo de consumo diretamente à criança. E mais: I - Os anúncios deverão $[\ldots]$ abster-se de: a) desmerecer valores sociais positivos, tais como $[\ldots]$ amizade, urbanidade, honestidade, justiça, generosidade e respeito a pessoas, animais e ao meio ambiente; b) provocar deliberadamente qualquer tipo de discriminação, em particular daqueles que, por qualquer motivo, não sejam consumidores do produto;

c) associar crianças e adolescentes a situações incompatíveis com sua condição, sejam elas ilegais, perigosas ou socialmente condenáveis; d) impor a noção de que o consumo do produto proporcione superioridade ou, na sua falta, a inferioridade;

e) provocar situações de constrangimento aos pais ou responsáveis, ou molestar terceiros, com o propósito de impingir o consumo;

f) empregar crianças e adolescentes como modelos para vocalizar apelo direto, recomendação ou sugestão de uso ou consumo, admitida, entretanto, a participação deles nas demonstrações pertinentes de serviço ou produto;

h) apregoar que produto destinado ao consumo por crianças e adolescentes contenha características peculiares que, na verdade, são encontradas em todos os similares;

i) utilizar situações de pressão psicológica ou violência $[. .$.$] capazes de infundir medo$ (CONAR, 2009). 
$\mathrm{O}$ anexo $\mathrm{H}$ - "Alimentos, refrigerantes, sucos e bebidas assemelhadas" - desse código complementa tais normas ao trazer artigos relacionados principalmente a produtos infantis (doces, salgadinhos, refrigerantes, etc.). Além de diretrizes equivalentes às do artigo 37 , como a que desautoriza o apelo direto a esse público, o anexo recomenda que as peças desses produtos não sugiram consumo exagerado, não os mostrem como substitutos de refeições básicas, incentivem, sempre que possível, a prática de exercícios e utilizem personagens do universo infantil e apresentadores de programas infantis em breaks comerciais e não como merchandising.

1. $[\ldots]$ os anúncios de produtos submetidos a este Anexo deverão: [...]

c. valorizar e encorajar, sempre que possível, a prática de exercícios físicos e atividades afins; d. abster-se de encorajar ou relevar o consumo excessivo nem apresentar situações que incentivem o consumo exagerado ou conflitem com esta recomendação; e. abster-se de menosprezar a importância da alimentação saudável, variada e balanceada; f. abster-se de apresentar qualquer produto como substituto das refeições básicas (desjejum, almoço e jantar), a menos que tal indicação esteja embasada em responsável opinião médica ou nutricional, reconhecida pela autoridade sanitária; [...] k. ao utilizar personagens do universo infantil ou apresentadores de programas dirigidos a este público-alvo, fazê-lo apenas nos intervalos comerciais, evidenciando a distinção entre a mensagem publicitária e o conteúdo editorial ou da programação; [...] 5. na publicidade dos produtos submetidos a este Anexo adotar-se-á interpretação a mais restritiva quando: [...] b.o produto for destinado ao consumo por crianças (CONAR, 2009).

Situa-se o ponto de retomada da discussão em 2003 porque, nessa época, o Conar realizou uma ampla revisão em seus anexos sobre bebidas alcoólicas. A mudança foi uma reação à quantidade de projetos de lei no Congresso destinados a proibir por completo anúncios desses produtos, tendo como um dos argumentos a possibilidade de o estilo criativo vigente em tais campanhas ser extremamente atrativo ao público infanto-juvenil. A partir das novas medidas aprovadas pelo órgão em setembro de 2003, os referidos anexos passaram a contar, nos itens "Princípio da proteção a crianças e adolescentes" e "Princípio do consumo com responsabilidade social", com as já conhecidas restrições sobre veicular somente entre 21 h30 e $6 \mathrm{~h}$; o anunciante não ter a intenção de dirigir a campanha a menores; e recomendações para evitar o interesse destes pelo produto, a saber: utilizar somente modelos que aparentem e/ou tenham mais de 25 anos; não apresentar recursos criativos comuns entre o público infantil, como personagens de desenho animado, animais ou bonecos; não utilizar apelos à sensualidade como principal conteúdo da mensagem ou tratar os modelos como objeto sexual (CONAR, 2009).

No fim de 2004, o PL n. 5.921/01 agitou esse debate ao passar por sua primeira análise no Congresso (REBOUÇAS, 2008). O PL pede a inclusão do seguinte item no artigo 37 do CDC: "S $2^{\circ}$ A. É também proibida a publicidade destinada a promover a venda de produtos infantis, assim considerados aqueles destinados apenas à criança" (ALANA, 2010).

Atualmente no CDC a publicidade infantil é contemplada de forma genérica na seção III Da Publicidade -, onde se lê que "é proibida toda publicidade enganosa ou abusiva", e, no parágrafo segundo, que "é abusiva, dentre outras, a publicidade [...] que se aproveite da deficiência de julgamento e experiência da criança" (CDC, 2009).

Em julho de 2008, ao passar pela Comissão de Defesa do Consumidor, o PL 5.921/01 foi aprovado na íntegra (CÂMARA, 2010). Já no segundo momento de votação, em outubro de 2009, o documento não foi aprovado em sua forma original, e sim com um substitutivo similar aos artigos em vigor, sob a justificativa de que a regulamentação existente é suficiente para tratar do assunto (GANEM, 2009). $\mathrm{Na}$ sequência, o novo texto proposto:

É abusiva, dentre outras, a publicidade [...] que $[\ldots]$ aproveite-se da deficiência de julgamento e experiência da criança, que seja capaz de induzir a criança a desrespeitar os valores éticos e sociais da pessoa e da família, desrespeite valores ambientais, que estimule o consumo excessivo, ou que seja capaz de induzir o consumidor a se comportar de forma prejudicial ou perigosa à sua saúde ou segurança (GANEM, 2009). 
Ainda faltam algumas etapas para saber se a propaganda infantil será ou não proibida. O PL 5.921/01 ainda receberá votações da Comissão de Ciência e Tecnologia e da Comissão de Redação e Justiça, para depois ir à votação final em plenário (GANEM, 2009).

Todo esse trâmite levou o mercado a se mobilizar ainda mais contra a proibição. Prova disso foi a $1^{\text {a }}$ Conferência de Marketing Infantil realizada em São Paulo, em novembro de 2009, no intuito de atualizar o setor sobre a medida iminente e buscar alternativas que substituam ações legais. O primeiro resultado prático do evento foi a proposta de criação de um fórum permanente para debater o tema, denominado Núcleo de Marketing Infantil Responsável, a ser formado por voluntários interessados na causa (FURTADO; GANEM, 2009). Em contrapartida, o documento teve aceitação na I Conferência Nacional de Comunicação (Confecom), realizada em dezembro de 2009, quando duas propostas a favor da proibição foram aprovadas (ALANA, 2010).

Desde 2006, a Anvisa também vem trabalhando numa regulamentação mais rigorosa para a propaganda de alimentos e bebidas com alto teor calórico e/ou baixo valor nutricional voltados ao público infantil (refrigerantes, doces, salgadinhos, biscoitos, etc.). Em 2006, a agência divulgou em seu site a Consulta Pública 71/06, contendo, além de diretrizes similares ao que consta no código do Conar, propostas de mudanças significativas como: inserção nesses anúncios de frases de advertência sobre os respectivos riscos do produto para obesidade, diabetes e outras doenças relacionadas à alimentação; proibição da utilização de ilustrações e personagens admirados pelo público infantil (cantores, apresentadores, personagens de desenho animado, etc.); proibição da realização de propagandas em instituições de ensino fundamental e em quaisquer outras cujo escopo seja fornecer cuidados às crianças; proibição de realização de campanhas beneficentes condicionadas à compra desse tipo de produtos (como o evento McDia Feliz, por exemplo); proibição da associação de brindes, prêmios e bonificações em geral a esses produtos; e delimitação da veiculação desses anúncios apenas entre 21 h e 6 h (ANVISA, 2010). A regulamentação completa proveniente dessa consulta pública deverá sair ainda em 2010, mas esse último item, o mais rigoroso do documento, já foi eliminado pelo órgão, atendendo a reivindicações da indústria alimentícia e aos esclarecimentos do governo sobre serem necessárias leis aprovadas em Congresso para que uma proibição desse porte seja implantada (LEITE; MANDELLI, 2010). Sobre a associação de bonificações a tais produtos, desde 2009 circula por lá o PL n. 4815/09 com esse mesmo objetivo, porém sem previsão de análise (IDEC, 2010).

Quanto a outras leis ou projetos de lei regulando a publicidade de categorias específicas de produtos voltados a menores, cita-se a Norma Brasileira de Comercialização de Alimentos para Lactentes e Crianças de Primeira Infância, Bicos, Chupetas e Mamadeiras (NBCAL), de autoria da Anvisa. ANBCAL consiste em um leque de documentos normativos que tratam da propaganda e rotulagem de alimentos e produtos voltados a recém-nascidos e crianças de até 3 anos-primeira infância-, comoleites, papinhas, chupetas e mamadeiras, visando a garantir o uso correto dessas mercadorias e a conscientização de que elas não substituem o aleitamento materno. As diretrizes ali contidas mais relacionadas à publicidade são as da RDC (Resolução) 222/02, intitulada Promoção Comercial de Alimentos Infantis (ligada à Lei n. 6.437, de 1977), determinando que esse tipo de anúncio deve apresentar frases de advertência sobre a necessidade do aleitamento materno e um conteúdo informativo sem qualquer ilustração de crianças ou outros personagens humanizados; e da RDC 221/02, proibindo qualquer propaganda de chupetas, bicos, mamadeiras e protetores de mamilo (ANVISA, 2010).

Além do Conar e das organizações de defesa dos direitos do consumidor em geral, como o Instituto de Defesa do Consumidor (Idec) e os diversos Procons, também atuam como uma espécie de observatório da ética publicitária, incluindo a voltada ao público infantil, principalmente as seguintes ONGs: Instituto Alana-Criança e Consumo, criado em 2005 por pedagogos, psicólogos e outros profissionais; Instituto Akatu pelo Consumo Consciente, concebido em 2000 como parte do Instituto Ethos de Empresas e Responsabilidade Social; e Ética na TV, com a campanha Quem Financia a Baixaria é Contra a Cidadania, iniciada em 2002 pela Comissão de Direitos Humanos e Minorias da Câmara dos Deputados (ALANA, 2010). Estes e outros organismos endossam o manifesto "Publicidade Infantil, Não", lançado na internet em 2009 e "assinado", até agora, por mais de sete mil cidadãos e 132 instituições (ALANA, 2010). 


\section{O cenário normativo da publicidade infantil na Espanha}

$\mathrm{Na}$ Espanha também não há uma lei proibindo a veiculação de publicidade infantil em alguma faixa de horário ou por completo, e nem princípios éticos com tal proposta (exceto para anúncios de produtos inadequados a esse público, como bebidas alcoólicas, a exemplo do Brasil) (AUC, 2009). No entanto, vários documentos e órgãos monitoram esse campo.

O organismo correlato ao Conar nesse país é a Asociación para la Autorregulación de la Comunicación Comercial (Autocontrol). Como principais documentos lá vigentes, direta ou indiretamente relacionados ao público infantil, citam-se os de autoria dessa instituição, como o Código de Conducta Publicitaria e pelo menos quatro de seus onze Códigos Sectoriales; a Ley General de Publicidad (LGP) (Lei n. 34/88); a Ley Televisión sin Fronteras (Lei n. 25/94) e, entre outros, o Código de Autorregulación sobre Contenidos Televisivos e Infancia (AUC, 2009).

A seção E - "Protección de niños y adolescentes" - do Código de Conducta Publicitaria, além de conter princípios genéricos, como não se transmitir mensagens que possam trazer prejuízo mental, moral ou físico às crianças, registra cuidados mais específicos, como o referente a evitar que tais anúncios gerem engano quanto a tamanho, funcionalidade, preço ou outras características, havendo exemplos, inclusive, de quando a peça estaria antiética (quando não se diz que é preciso pilhas para obter a função divulgada, por exemplo) (AUTOCONTROL, 2009).

\section{E. - PROTECCIÓN DE NIÑOS Y ADOLESCENTES}

28. - [...] no deberá contener declaraciones o presentaciones visuales que puedan producirles perjuicio mental, moral o físico. Se tendrá especial cuidado para asegurar que los anuncios no engañen o induzcan a error a los niños en lo que se refiere al tamaño real, valor, naturaleza, durabilidad y rendimiento del producto anunciado. Si se requiere el uso de otros artículos para su correcta utilización (por ejemplo, pilas) o para conseguir el resultado descrito o mostrado (por ejemplo, pintura) ello debe quedar explícitamente expresado.
Los anuncios no deben sobrestimar el nivel de habilidad o el límite de edad de los niños para poder disfrutar o utilizar los productos (AUTOCONTROL, 2009).

Os Códigos Sectoriales mais focados no público infantil resumem-se nos seguintes: Código de Autorregulación de la Publicidad de Alimentos Dirigida a Menores, Prevención dela Obesidady Salud - Código Paos; Código Deontológico para Publicidad Infantil de la Asociación Española de Fabricantes de Juguetes, y Unión de Consumidores de España (UCE), e Código de Autorregulación Publicitária de Cerveceros de España (AUTOCONTROL, 2009).

Pelo Código Paos, criado em 2005 pela Federación de Industrias de Alimentación y Bebidas (FIAB), as empresas que endossaram sua criação devem encaminhar para consulta prévia da Autocontrol todos os anúncios de alimentos voltados a menores de 12 anos, bem como os dirigidos a outros públicos, mas com veiculação planejada para horários de proteção reforçada previstos no Código de Autorregulación sobre Contenidos Televisivos e Infancia (por exemplo, $8 \mathrm{~h}$ às $9 \mathrm{~h}$ e $17 \mathrm{~h}$ às $20 \mathrm{~h}$, em dias úteis, e $9 \mathrm{~h}$ às $12 \mathrm{~h}$, em fins de semana) (AUTOCONTROL, 2009).

4. - Consulta previa

[...] las empresas adheridas al mismo se comprometen a enviar al Gabinete Técnico de Autocontrol, para su examen previo a través del sistema de consulta previa o "copy advice" confidencial y vinculante, todos los anuncios dirigidos a menores de hasta 12 años y los anuncios televisivos de alimentos y bebidas cuya emisión vaya a llevarse a cabo en las franjas horarias de protección reforzada de la infancia fijadas en el Código de Autorregulación sobre Contenidos Televisivos e Infancia y el Convenio para el Fomento de la Autorregulación sobre Contenidos Televisivos e Infancia suscrito por los operadores de televisión y el Gobierno en diciembre de 2004 (AUTOCONTROL, 2009).

Entre os demais artigos do Código Paos, estão normas idênticas ou similares às do Conar sobre o anúncio: não conter apelo direto ao consumo, incluindo frases no imperativo; não sugerir que a criança insista com os adultos para que comprem o produto ou não desvalorizar quem não o der aos 
filhos; e não fazer associações de que o produto pode garantir maior prestígio e outras habilidades inalcançáveis só com o seu uso.

9.-[...] no debehacer un llamamiento directo a los menores a la compra del producto anunciado explotando su inexperiencia o su credulidad, ni incitarles a que pidan o persuadan a sus padres o a otras personas para que compren los productos anunciados. [...] tampoco deben sugerir que un padre o un adulto que compra un producto alimenticio o una bebida a un niño es un padre o un adulto mejor, más inteligente o más generoso que el que no lo hace.

11. - [...] no debe dar la impresión de que adquirir o consumir un alimento o bebida dará una mayor aceptación del niño entre sus amigos. [...] tampoco debe implicar que no adquirir o consumir un producto provocará el rechazo del niño entre sus compañeros. Los anuncios no deben sugerir que la compra y el uso del producto aportarán al usuario el prestigio, las habilidades y otras cualidades especiales de los personajes que aparecen en el anuncio (AUTOCONTROL, 2009).

Há no documento, ainda, recomendações sobre não se utilizar palavras como "somente" ou "nada mais" para qualificar o atributo do preço e outras normas orientando que personagens cativos do público infantil (apresentadores, figuras de desenho animado, etc.) só apareçam no caso de promoções referentes a produtos ligados a eles, de modo que não sejam diretamente associados aos alimentos e bebidas ofertados (por exemplo, só poderá haver o personagem Shrek na peça caso se trate de uma promoção envolvendo DVD ou outro item de filmes Shrek). Contudo, os artigos permitem que tais anúncios utilizem esses personagens se eles forem criados exclusivamente para a marca (o Tigre da Kellogg's ${ }^{\circledR}$, então, não seria uma infração).

12. - Los precios deben expresarse clara y concretamente. No deben utilizarse reduccionismos como "sólo" o "nada más". En todo caso, los anuncios en los que se indique el precio deben cumplir todos los requisitos fundamentales de la legislación nacional, en particular los reglamentos sobre la protección del consumidor. [...]
13.1. [...] no participarán ni aparecerán personajes especialmente próximos al público menor de edad, tales como, por ejemplo, presentadores de programas infantiles, personajes -reales o ficticios-de películas o series de ficción, u otros. [...] podrán mostrar imágenes que reproduzcan escenas de un determinado programa infantil, película o serie si esta guarda relación directa con alguna promoción que se esté llevando a cabo (por ejemplo, obsequio de un DVD de una serie infantil por la compra de un determinado alimento o bebida). [...] no se podrá realizar alusión alguna, directa o indirecta, al producto promocionado ni podrá aparecer éste en pantalla. Una vez finalicen dichas escenas, y de forma claramente separada, se podrá mostrar el producto anunciado y se podrá informar sobre sus características, aunque nunca empleando la imagen o la voz de los personajes de dichos programas, espacios o películas. [...] se excluirán de tales exigencias aquellos personajes de ficción creados específicamente con fines publicitarios relacionados con el producto promocionado y que, por consiguiente, resulten conocidos entre el público infantil exclusivamente como resultado de su participación en la publicidad de ese producto.

13.2. La publicidad de alimentos o bebidas dirigida a menores no podrá mostrar personajes conocidos o famosos entre el público en general que gocen de un alto grado de popularidad entre el público infantil (AUTOCONTROL, 2009).

Já os artigos a seguir trazem quase o mesmo que o anexo $\mathrm{H}$ sobre a peça não sugerir consumo excessivo do produto, não denotar que este seja substituto para alguma refeição e não desvalorizar a importância de hábitos saudáveis, como praticar exercícios. Detalha-se, ainda, que em cenas à mesa deve-se mostrar uma quantidade razoável de alimentos saudáveis.

23. [...] no deberán promover o presentar hábitos de alimentación o estilos de vida poco saludables tales como comer o beber de forma inmoderada, excesiva o compulsiva, ni deberán fomentar, aprobar o presentar de forma condescendiente hábitos de vida sedentarios. [...] no deberá mostrar el alimento o bebida promocionado en cantidades excesivas 
o desproporcionadas. Asimismo, cuando la publicidad presente el alimento o bebida promocionado en el contexto de una comida, deberá mostrarse acompañado de una variedad razonable de alimentos con el fin de que el mensaje publicitario fomente su consumo como parte de una dieta variada y equilibrada. 24. [...] ningún producto puede presentarse como sustitutivo de ninguna de las tres comidas principales (desayuno, comida y cena).

25. [...] no deberá minusvalorar la importancia de hábitos de vida saludables tales como [...] alimentación variada y equilibrada o la realización de actividad física (AUTOCONTROL, 2009).

É também no Código Paos que se encontra uma definição precisa sobre o que seria a publicidade voltada a crianças, destacando que um anúncio deve ser assim classificado levando-se em conta principalmente três fatores: a natureza do produto anunciado, o conteúdo da peça e o local e horário onde ocorre a veiculação (AUTOCONTROL, 2009). Comolembra Rebouças (2008, p. 5), a citada Lei n. 72, de Québec, utiliza a mesma delimitação.

Instituído em 1993 pela Asociación Española de Fabricantes de Juguetes e pela Unión de Consumidores de España (UCE), e desde 2003 adotado também pela Autocontrol, o Código Deontológico para Publicidad Infantil de la Asociación Española de Fabricantes de Juguetes y UCE traz, por exemplo, normas ressaltando que o anúncio: não deve induzir a erro quanto a tamanho, velocidade, funcionamento, cor e durabilidade dos brinquedos; deve apresentar com clareza, caso pertinente, alertas como "você que terá que montá-lo"; não deve associar a aquisição do brinquedo à força, inteligência, popularidade; e deve esclarecer, no caso de concursos, que as chances de ganhar são míninas, valendo-se de expressões como "muitos participarão, poucos ganharão” (AUTOCONTROL, 2009).

\section{Directriz 1}

1. Las presentaciones escritas, sonoras y visuales no deben equivocar a los niños/as sobre las características del producto o sus prestaciones. [...]

2. [...] no debería equivocara los niños/as sobre los benefícios derivados del uso del producto. Entre ellos [...]: la adquisición de fortaleza, estatus, popularidad, crecimiento, habilidad e inteligencia. [...] El uso de un lenguaje simplificado, como "tienes que montarlo tú" en lugar de "se requiere el ensamblado", aumenta significativamente la comprensión.

Directriz 10

Concursos. En los concursos publicitarios para niños/as no se pueden dar expectativas irreales sobre las posibilidades de ganar o sobre el premio que se puede ganar. Por lo tanto: 1 . El(los) premio(s) debe indicarse claramente. 2. Las "posibilidades" de ganar deben indicarse claramente en la parte audible del anuncio, por ejemplo: "muchos participarán, pocos ganarán" (AUTOCONTROL, 2009).

Quanto ao Código de Autorregulación Publicitaria de Cerveceros de España, os artigos relacionados à publicidade infantil são semelhantes aos do Conar. Nele recomenda-se, por exemplo, que: não sejam veiculados tais anúncios antes das 20 h30 e durante ou imediatamente antes e depois de programas infantis; não seja associado o consumo da bebida à maturidade ou a outros aspectos positivos de personalidade; e não sejam apresentados desenhos e outros recursos criativos típicos do mundo infanto-juvenil (animações, entre outros) (AUTOCONTROL, 2009).

$\mathrm{Na}$ LGP, as restrições são menos precisas do que as aqui descritas, ressaltando apenas, no "Título II - De la Publicidad Ilícita", que "es ilícita: 1. La publicidad que atente contra la dignidad de la persona o vulnere los valores y derechos reconocidos en la Constitución, especialmente en lo que se refiere a la infancia, la juventud y la mujer" (AUC, 2009).

Em 2004, a Confederación Española de Organizaciones de Amas de Casa, Consumidores e Usuarios (CEACCU) solicitou ao Ministério da Saúde espanhol a proibição, em intervalos de programas infantis televisivos, de anúncios de alimentos industrializados (doces, salgadinhos, etc.), não resultando ainda em nenhum novo texto normativo (MONTOYA VILAR, 2007, p. 21-22).

\section{Análise comparativa: em busca de uma conclusão}

A Espanha tem mais códigos de ética específicos para tratar da publicidade infantil, mais documentos legais exclusivos da área, mais órgãos 
fiscalizando o setor e um acordo para que a indústria alimentícia voltada a menores não veicule anúncios sem antes enviá-los à Autocontrol, a instituição autorregulamentadora do país. No Brasil, o código do Conar contempla a maioria das diretrizes desse leque normativo e as novas propostas regulamentadoras sob análise por aqui parecem mostrar que a sociedade brasileira está ainda mais interessada que a espanhola em ampliar as restrições a essa categoria de anúncios.

Diretrizes inexistentes na seção 11 "Crianças e jovens" - do referido código, por exemplo, constam no seu anexo $\mathrm{H}$ - "Alimentos, refrigerantes, sucos e bebidas assemelhadas", e vice-versa. É o caso de recomendações para que o anúncio não utilize a forma imperativa com a criança ou promova de outra forma o diálogo direto com ela; não apresente cenas que sugiram o consumo excessivo de alimentos e bebidas pouco saudáveis ou os coloquem como substitutos para refeições; não confundam quanto às reais características dos produtos ofertados (tamanho, etc.); não sugiram que ele possa conferir prestígio, força, inteligência; não mostrem quem não consome como inferior; não incentivem o menor a convencer os pais a comprar, entre outros princípios.

Diferentemente da Espanha, circulam no Brasil projetos com propostas bastante polêmicas, como o 5921/01 defendendo a proibição completa da publicidade infantil, e o regulamento descrito na Consulta 71/06 da Anvisa. A proposta mais ousada desse último documento, a delimitação, para o horário das $21 \mathrm{~h}$ às $6 \mathrm{~h}$, da veiculação de anúncios de alimentos e bebidas pouco saudáveis voltados a crianças já foi dissolvida em março deste ano em resposta às mobilizações do mercado. Outras, como a referente à inserção de frases de advertência sobre riscos desses produtos à saúde, serão consolidadas, e estão pendentes, por exemplo, as que tratam do fim de doações oriundas da venda de tais itens e da impraticabilidade de se anunciar em escolas e outras instituições de cuidados ao público infantil.

E quanto a princípios vigentes na Espanha ainda não contemplados nas normas brasileiras, cita-se que eles já estão cogitados em tais projetos, como a proibição do uso de personagens de alto poder atrativo para crianças, entre eles celebridades e figuras de animações. $\mathrm{Na}$ verdade, se essa diretriz for adotada, a propaganda brasileira terá ainda mais restrições que a espanhola nesse sentido, pois lá os códigos não condenam o uso desse tipo de ilustrações se elas forem exclusivas de campanhas publicitárias ou caso se refiram a brindes ofertados.

Pode-se dizer que a medida mais rigorosa espanhola não vislumbrada no Brasil consiste, como foi mencionado no início desta conclusão, no dever de anunciantes de alimentos e bebidas de alto teor calórico/baixo valor nutricional, tipicamente atrativos para crianças, terem de enviar suas peças publicitárias à Autocontrol antes de serem veiculadas, para que o órgão avalie sua adequação ética. Também se observa um maior cuidado da Espanha com esse público, tanto em diretrizes voltadas a definir o que é publicidade infantil, quando em alguns artigos específicos, como alertando sobre não mostrar algo que o produto não ofereça (brinquedos, no caso). No primeiro caso, encontra-se, pelo menos num de seus códigos de ética, focado especificamente na publicidade de certos alimentos e bebidas, a delimitação de que para se classificar uma publicidade voltada a crianças, assim como é em Québec, devese levar em conta a natureza do produto ofertado, os recursos criativos dos anúncios e onde e quando será a veiculação. No segundo contexto, notam-se proposições mencionando a necessidade de, por exemplo, enfatizar que é preciso pilhas para atingir a performance divulgada; utilizar, em anúncios de concursos e sorteios, frases que ressaltem as poucas chances de se ganhar; apresentar vários produtos saudáveis em cenas junto a uma mesa de refeições, bem como não usar reducionismos no preço divulgado.

Deve-se pensar bem se é interessante o procedimento espanhol de utilizar instituições como filtro para anúncios antiéticos, já que isso pode significar transferir a responsabilidade social de anunciantes e agências para organismos específicos e assim dificultar transformações efetivas do mercado rumo a uma sociedade de consumo mais ética. No entanto, o cuidado do país em exemplificar melhores princípios registrados nos documentos normativos poderia ser seguido também por aqui. Afinal, há uma lacuna significativa em nossa normatização tanto na definição do que é publicidade voltada a crianças quanto em indicadores do que seriam, entre outros casos, cenas sem "apelo direto" vocalizado por modelos publicitários, ou recursos criativos não encorajadores de consumo excessivo de alimentos e bebidas. Do mesmo modo, os artigos também deixam a desejar quanto a contraexemplos antiéticos. É por essas e outras razões que são prementes pesquisas 
que rastreiem tais minúcias, da mesma forma como continuar a discussão em torno das novas propostas regulamentadoras em trâmite.

Enfim, tem-se aqui algumas reflexões e um modelo normativo a mais que talvez possam ser úteis neste relevante e atual debate para se chegar a uma normatização mais clara, abrangente e justa em relação ao peculiar público infantil.

\section{Referências}

AGÊNCIA NACIONAL DE VIGILÂNCIA SANITÁRIA-ANVISA. Detalhes da Consulta Pública n. 71/2006-Alimentos. Disponível em: <http:/ /www. anvisa.gov.br/propaganda/consulta_71_2006.htm\#>. Acesso em: 10 fev. 2010.

ASOCIACIÓN DE USUARIOS DE LA COMUNICACIÓN - AUC. Legislación. Disponível em: <http://www.auc.es/>. Acesso em: 15 jan. 2009.

ASOCIACIÓN PARA LA AUTORREGULACIÓN DE LA COMUNICACIÓN COMERCIAL AUTOCONTROL. Quéhacemos. Códigos. Disponível em: <http//www.autocontrol.es>. Acesso em: 16 jan. 2009 .

CÂMARADOSDEPUTADOS. Comissão aprova proibição de propaganda dirigida à criança. Disponível em: <camara.gov.br/agencia/noticias/124768.html>. Acesso em: 10 fev. 2010.

CÓDIGO DE DEFESA DO CONSUMIDOR - CDC. Disponível em: <http://www.mj.gov.br/DPDC/servicos/legislacao/cdc.htm>. Acesso em: 20 jan. 2009.

CÓDIGO NACIONAL DE AUTORREGULAMENTAÇÃO PUBLICITÁRIA - CONAR. Disponível em: $<$ http//www.conar.org.br>. Acesso em: 14 jul. 2009.

BREE, J. Los niños, el consumo y el marketing. Barcelona: Paidós, 1995.

FURTADO, J.; GANEM, P. Fim do silêncio: empresas se mobilizam para defender a comunicação de produtos destinados a crianças e reforçam a importância da autorregulamentação. Meio \& Mensagem, ano 31, n. 1384, 9 nov. 2009.

GANEM, P. Publicidade infantil é votada por comissão da Câmara. Meio \& Mensagem, 7 out. de 2009.
INSTITUTO DE DEFESA DO CONSUMIDORIDEC. Procuradoria propõe liminar contra venda associada de lanches e brindes. Disponível em: $<$ http:/ / www.idec.org.br/emacao.asp?id=1963\#>. Acesso em: 20 fev. 2010.

INSTITUTO ALANA - CRIANÇA E CONSUMO. PL $\mathrm{n}^{0} 5.921$ é votado na comissão de desenvolvimento econômico. Disponível em: <http:// www.alana.org.br/CriancaConsumo/NoticiaIntegra. aspx?id=6439\&origem=23 > . Acesso em: 25 jan. 2010.

KAPFERER, J. N. L'enfant el la publicité. Paris: Bordas, 1985.

KLEIN, N. Sem logo: a tirania das marcas em um planeta vendido. 4. ed. Rio de Janeiro: Record, 2004.

LEITE, F; MANDELLI, M. Anvisa abranda regra para propaganda infantil. O Estado de S. Paulo, 6 mar. 2010. Disponível em: <http://www.estadao.com.br/ estadaodehoje/20100306/not_imp520316>. Acesso em: 7 mar. 2010.

MOMBERGER, N. F. A publicidade dirigida às crianças e adolescentes: regulamentações e restrições. Porto Alegre: Memória Jurídica, 2002.

MONTOYA VILAR, N. La influencia de la publicidad audiovisual en los niños: estudios y métodos de investigación. Barcelona: Bosch, 2007.

PORTAL APRENDIZ. Consumo consciente. São Paulo, 11 out. 2007. Disponível em: <http://aprendiz. uol.com.br/content/swedregine.mmp>. Acesso em: 10 fev. 2010.

REBOUÇAS, E. Os desafios para a regulamentação da publicidade destinada a crianças e adolescentes: soluções canadenses e reticências à brasileira. Intercom-Revista Brasileira de Ciências da Comunicação, v. 31, n. 2, p. 75-97, jul./dez. 2008.

SCHNEIDER, A. CONAR 25 anos: ética na prática. São Paulo: Terceiro Nome, 2005.

Recebido: 15/03/2010 Received: 03/15/2010

Aprovado: 30/06/2010 Approved: 06/30/2010 